\title{
DEVELOPMENT OF NANO METAL POWDERS FOR ULTRA-LOW FIRE MLC INNER ELECTRODES*
}

\author{
FERNANDO DE LA VEGA ${ }^{\dagger}$, EYNAT MATZNER, ERIK KHASIN, \\ AHARON NAOR and ASAF GREENSHPAN \\ NanoPowders Industries, 7 Bareket St., Caesaria Industrial Park 38900, Israel
}

(Received December 2001)

\begin{abstract}
The need to reduce metal content, especially Palladium content in the multi layer ceramic components is driven by two motives. The first is the need to reduce material costs which has become a major issue due to the sharp rise and instability of palladium price. The second motive is the need to build components with ever-growing number of layers, in order to achieve better performance.

In this paper, a series of new metal powders, which were developed by NanoPowders Industries (NPI), will be discussed. These powders vary in composition, from pure silver, to silver-palladium, silver-platinum and silvergold alloys. These powders are of very fine particle size. They open a broad working window for MLC design.

The different properties of the powders will be discussed in this paper, including melting and sintering behavior.
\end{abstract}

Keywords: Metal powders, MLC inner electrodes, nano powders, silver-palladium powders, capacitor inner electrodes.

\section{INTRODUCTION}

In the last 4 years, prices of palladium reached new heights and were generally unstable and hard to predict (see Fig. 1). The result was high pressure on components producers to find cheaper and more stable alternatives. Moving to base metals electrodes was one strategy taken by many producers. At the same time a move to low fire systems started. The idea in "low fire" systems is to develop dielectric and metal powders (mainly metal alloys of silver), suitable for sintering at low temperatures without harming the performance of the component. The lower the sintering temperature, the lower the palladium content required in the powder and therefore the cost is lower. During the past four years there has been a constant move towards lower palladium concentrations, from pure palladium electrodes, to $30 \%$ palladium, $70 \%$ silver $(\mathrm{w} / \mathrm{w})$, to $15 \%$ palladium and even lower. The new generation of capacitors will use $5 \%$ palladium only, with a sintering temperature of about $940{ }^{\circ} \mathrm{C}$., compared with $1100-1200{ }^{\circ} \mathrm{C}$ [2] for a $100 \%$ palladium electrode. Parallel to this trend big efforts are been made to decrease the particle size of the powder from 1-2 $\mu \mathrm{m}$ to less than $0.5 \mu \mathrm{m}$. Lower particle size powders will enable the production of even thinner electrodes and more compact components, decreasing even further the costs and enhancing the performance.

\footnotetext{
* An earlier version of this paper was published in the Proceedings of the 15th Annual European Passive Components Conference (CARTS-EUROPE 2001), 15-19 October 2001, pp. 107-111.

$\dagger$ Corresponding author. Tel.: +972-4-6379520; Fax: +972-4-6379526; E-mail: delavega@nanopowders.com
} 


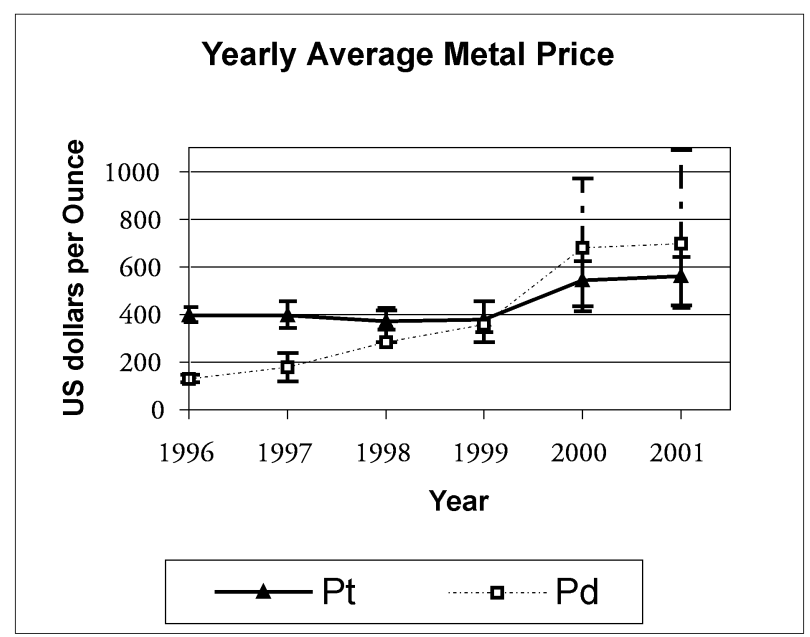

FIGURE 1 Palladium and platinum prices, 1996 to 2001 [1].

NanoPowders Industries (NPI) has developed in the last years its patented technology, and is now producing silver and silver alloyed powders in particle sizes ranging between $2.0-0.05 \mu \mathrm{m}$. NPI's technology allows the company to produce real alloy, solid solution powders of a variety of silver alloys such as: silver/palladium, silver/platinum, silver/ gold and silver/copper. The ratios between the two metals depend on their mutual solubility.

We have developed several powder series suitable for electronic components applications. The powders are based on silver alloys of palladium, platinum, gold and copper. By changing the metals and the composition we can cover a wide range of properties, which open for the component designer and producer a wide window of opportunities, including the possibility to change from palladium to platinum or gold and in this manner overcome the price instability and keep costs stable and low (see Fig. 1). The silver/palladium powders range from $15 \%(\mathrm{w} / \mathrm{w})$ palladium and lower palladium concentrations. Silver/platinum is available in compositions up to $5 \%(\mathrm{w} / \mathrm{w})$ platinum. New products are being added to each series.

In this paper we report the performance of three silver/platinum powders. We will show that these powders have excellent performances in both NPO and X7R capacitors and may replace the common silver/palladium powders in the new generation of low fire systems.

\section{NANOPOWDERS INDUSTRIES PROCESS}

NPI's patented technology is unique in the metal powder industry. It consists of three steps:

Step 1: Metallurgical - forming an alloy according to requested product and choosing the right crystal structure for the production of the powder.

Step 2: Hydrometallurgical - extracting powder from the alloy by a chemical reaction.

Step 3: Morphology adjustment by special milling equipment, and chemical surface treatment.

The first step determines the composition of the final powder. Particle size distribution, surface area and dispersability are controlled in the second and third steps.

This technology enables the production of a wide range of metal compositions and particle size distributions, especially alloys which have a solid solution phase. Powders of real nano- 


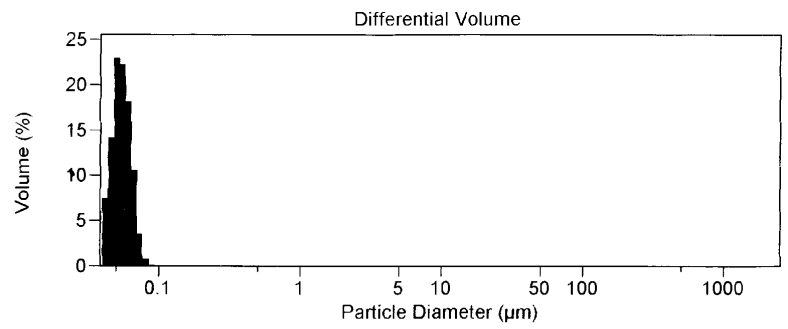

Volume Statistics (Arithmetic)

as586b1.\$01

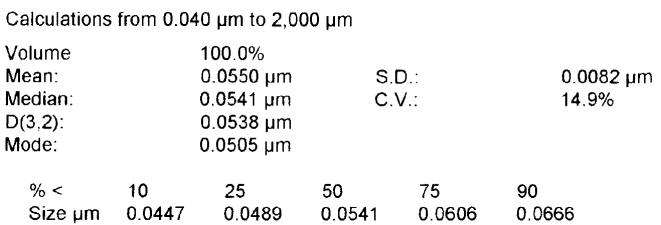

FIGURE 2 Particle size distribution of silver nano-powder.

metric size (D90 < $0.1 \mu \mathrm{m}$ ) are produced (see Figs. 2 and 3), and also powders of larger sizes such as $0.2,0.4$ and 1 micron. The fine powders allow the component producer to use lower metal loadings in the electrodes and still get good continuity and electrical performance. This is another added value to the component producer, which can save up to $20 \%$ of the metal cost.

\section{PROPERTIES OF SILVER/PRECIOUS METALS POWDERS}

Three grades of silver/platinum powders are reported in this study, with the following metal ratios (w/w): \#492 - Ag/Pt 98:2, \#494 - Ag/Pt 96:4 and \#495 - Ag/Pt 95:5.

These powders will be compared to silver/palladium products as follows: \#4510 - Ag/Pd 90:10, \#455 - Ag/Pd 95:5, \#452 - Ag/Pd 98:2.

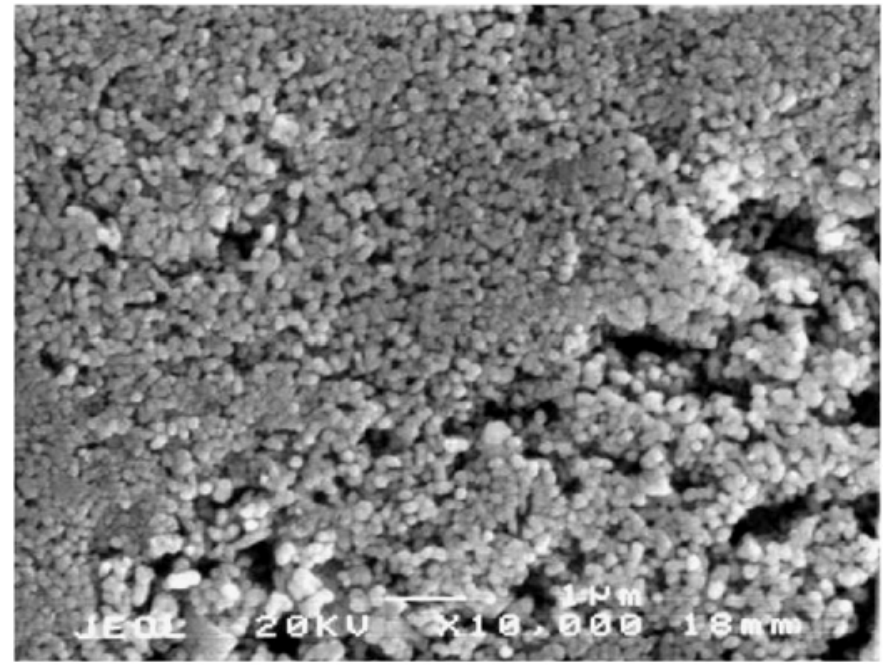

FIGURE 3 SEM picture of silver nano-powder. 


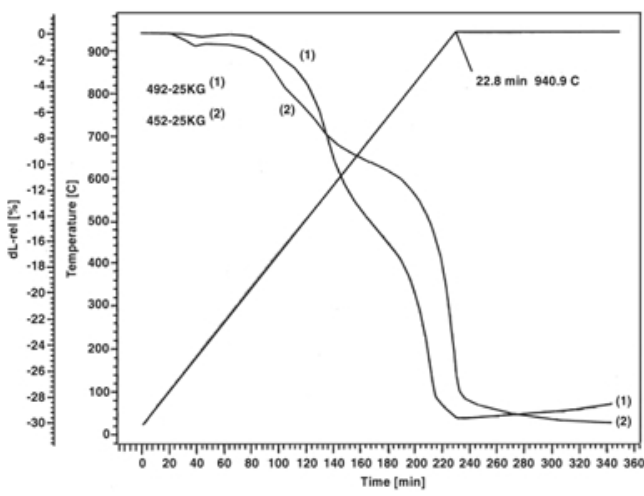

FIGURE 3 Dilatometer analysis of 98:2 powders \#452 (Ag/Pd) and \#492 (Ag/Pt).

The sintering temperature is directly related to the melting temperature. Due to the manner that components are produced the sintering temperature of the metal has to be related to the sintering temperature of the ceramics used. Great care has to be taken to combine both. Silver alone would be the natural choice for these applications, low melting temperature and low price but it is usually not suitable for these applications due to a too low melting temperature, chemical instability and problems related to silver migration into the dielectric layer. To overcome these problems silver-palladium alloys have been used. The most common silver alloys contain between ten to thirty percent $(\mathrm{w} / \mathrm{w})$ palladium. Nowadays the trend is to use even lower concentrations of palladium. The limit is the sintering temperature of the ceramic. We have found that silver platinum alloys behave similar to the silver palladium alloys, with the advantage that the price of platinum is usually lower and much more stable than the price of palladium (see Fig. 1). The silver-platinum powders are available in the range of up to 5 percent $(\mathrm{w} / \mathrm{w})$ platinum. The reason for the lower platinum content compared to palladium is found in the phase diagram of silver/platinum, which is rather complicated. In the silver-platinum system the solid solution structure exists only at low concentrations of platinum, up to 4-5 percent $(\mathrm{w} / \mathrm{w})$. Above 5 percent platinum, new phases will appear which alter the performance of the powder. Melting temperatures and metal costs of these alloys are shown in Tables I and II.

From the data shown in Tables I and II we can identify several trends:

a. At the same composition, powders containing platinum have slightly lower melting points than the palladium equivalents, between 5 and 11 degrees less. Gold-silver alloys have even lower melting temperatures.

TABLE I Melting Temperature of Different Metal Alloys Powders.

\begin{tabular}{lccr}
\hline & \multicolumn{3}{c}{ Minor metal in alloy } \\
\cline { 2 - 4 } Silver percentage & \multicolumn{1}{c}{$P d$} & $P t$ & $A u$ \\
\hline 100 & 961.9 & 961.9 & 961.9 \\
98 & 973.3 & 967.4 & \\
96 & & 977.3 & \\
95 & 993.4 & 982 & 970.2 \\
90 & 1037.7 & & 1064.4 \\
0 & 1555 & 1769 & \\
\hline
\end{tabular}

Melting temperature $-{ }^{\circ} \mathrm{C}$ as determined by DTA analysis. 
TABLE II Metal Price of Different Metal Alloys Powders.

\begin{tabular}{rrcr}
\hline & \multicolumn{3}{c}{ Minor metal in alloy } \\
\cline { 2 - 4 } Silver & \multicolumn{1}{c}{$P d$} & $P t$ & $A u$ \\
\hline 100 & 137 & 137 & 137 \\
98 & 462 & 474 & \\
96 & 787 & 810 & \\
95 & 950 & 978 & 995 \\
90 & 1763 & & 9,173 \\
0 & 13,397 & 13,961 & \\
\hline
\end{tabular}

Price - in \$/kg. July 19, 2001 [1].

b. Melting temperatures are proportional to the composition of the alloy.

c. According to Table I, we can conclude that with platinum containing powders, the component producer can achieve similar sintering temperatures compared to the palladium based powders.

d. These powders are suitable for low firing temperature applications.

e. Silver alloys with palladium, platinum and gold are much cheaper than palladium.

\section{BEHAVIOR OF SILVER/PALLADIUM AND SILVER/PLATINUM POWDERS}

During the firing step in the composite production process the powders undergo changes due to the rearrangement of the atom array induced by diffusion, which occurs at below melting temperatures (sintering process). One of the most notorious changes is the density of the powder. These changes can be measured in a dilatometer. Figure 3 shows the TMA analysis of \#492 and \#452 powders. It is shown that the sintering behavior of silver/palladium and silver/platinum of the same composition is basically the same. The densification process of both powders starts at $350{ }^{\circ} \mathrm{C}$ and by $900{ }^{\circ} \mathrm{C}$, the volume is reduced by about $30 \%$.

For powders with higher melting points: \#455 and \#495, the same behavior is observed (see Fig. 4), with the densification process starting at $400{ }^{\circ} \mathrm{C}$ and terminating at $950{ }^{\circ} \mathrm{C}$. Increasing the concentration of the high melting temperature component will generally decrease the degree of final shrinkage.

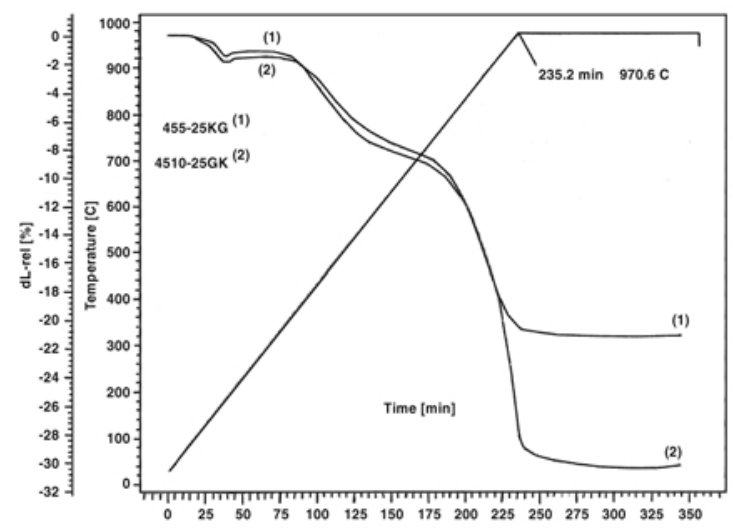

FIGURE 4 Dilatometer analysis of \#455 (95:5) and \#4510 (90:10) Ag/Pd powders. 


\section{PARTICLE SIZE DISTRIBUTION}

NPI's process for production of powders includes a morphology adjustment step in which a chemical surface treatment and special milling enables the deaglomeration of the powder. The powder particle size range achieved for the silver/palladium powders is between 1.5 and 0.5 (D50 as measured by a Coulter instrument). See sample in Figure 5.
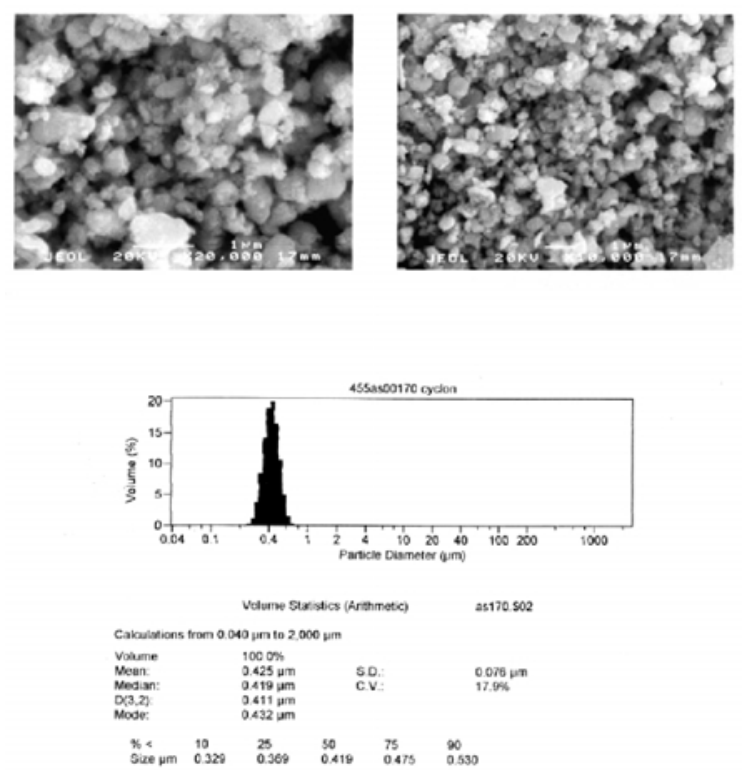

FIGURE 5 Particle size distribution and SEM pictures, \#455 (Ag/Pd 95:5) powder.
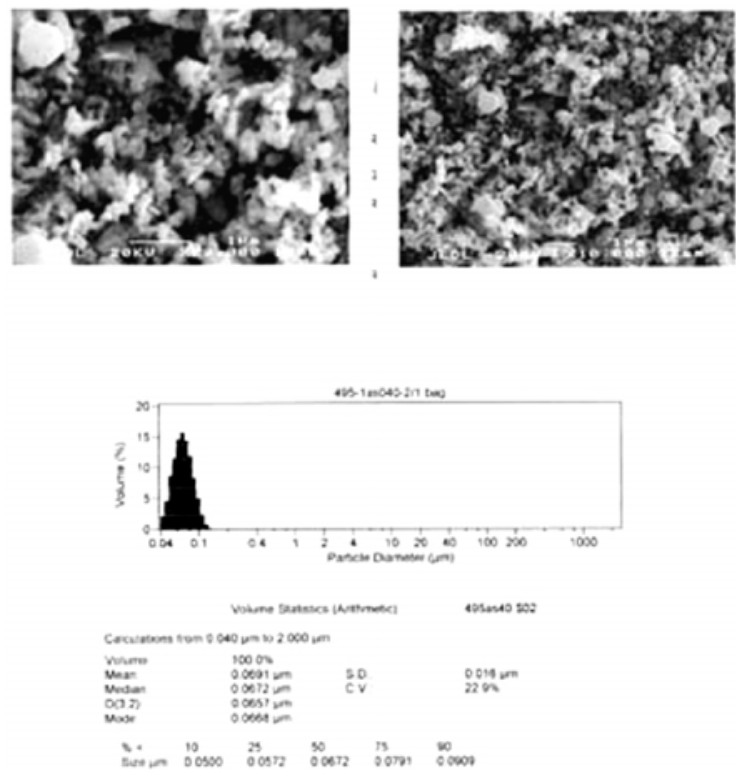

FIGURE 6 Particle size distribution and SEM pictures, \#495 (Ag/Pt 95:5) powder. 
Our deaglomeration technology enables us to achieve even smaller particle size distributions, D50 around 0.07 and D90 around 0.1 for the silver/platinum powders (as measured by a Coulter instrument). See sample in Figure 6.

\section{CAPACITOR PRODUCTION}

The powders are converted to pastes in order to print the electrodes in the capacitor production process. The dispersability of the pastes is an important feature, which is influenced by the metal powder. It is possible that dispersability characteristics will change when powders from different sources are used. Metal producers treat the surface of their powders in different manners according to their specific technologies. Silver/palladium and silver/platinum powders produced by NPI behave in a similar way, based on the similar surface treatment, which they are subject to.

\section{PALLADIUM CONCENTRATION}

NPO type capacitors were produced to check the behavior of $\mathrm{Ag} / \mathrm{Pd}$ and the influence of $\mathrm{Pd}$ concentration on the sintering temperature. Two compositions were tested, 95/5 and 90/10 $(\mathrm{w} / \mathrm{w}) \mathrm{Ag} / \mathrm{Pd}$. The capacitors were sintered at different temperatures, the electrical properties obtained were measured and the layer continuity was checked, see Tables III and IV and Figures 7 and 8.

TABLE III Comparison of Electrical Performance at Different Sintering Temperatures, Ag/Pd 95/5.

\begin{tabular}{lcccc}
\hline Sintering Temp. ${ }^{\circ} \mathrm{C}$ & 900 & 920 & 940 & 960 \\
\hline Capacity & & & & \\
$\quad$ Avg. (pF) & 97.35 & 100.96 & 101.60 & 99.60 \\
$\quad$ Std. & 2.5 & 1.7 & 2.1 & 2.9 \\
Df & 0.063 & 0.051 & 0.052 & 0.050 \\
$\quad$ Max. & 0.050 & 0.049 & 0.048 & 0.046 \\
$\quad$ Min. & 1685 & 1685 & 1642 & 1628 \\
Breakdown voltage & 2112 & 1887 & 1904 & 1919 \\
$\quad$ Min. & & & & \\
$\quad$ Max. & & & \\
\hline
\end{tabular}

TABLE IV Comparison of Electrical Performance at Different Sintering Temperatures, Ag/Pd 90/10.

\begin{tabular}{lcccc}
\hline Sintering Temp. ${ }^{\circ} \mathrm{C}$ & 900 & 920 & 940 & 960 \\
\hline Capacity & & & & \\
$\quad$ Avg. (pF) & 95.7 & 101.4 & 2.2 & 100.7 \\
$\quad$ Std. & 1.5 & 1.7 & 0.053 & 2.1 \\
Df & & & 0.050 & 0.052 \\
$\quad$ Max. & 0.058 & 0.052 & 1743 & 0.048 \\
$\quad$ Min. & 0.054 & 0.049 & 1960 & 1757 \\
Breakdown voltage & 1938 & 1805 & 1960 \\
$\quad$ Min. & 2351 & 2022 & & \\
$\quad$ Max. & & & & \\
\hline
\end{tabular}




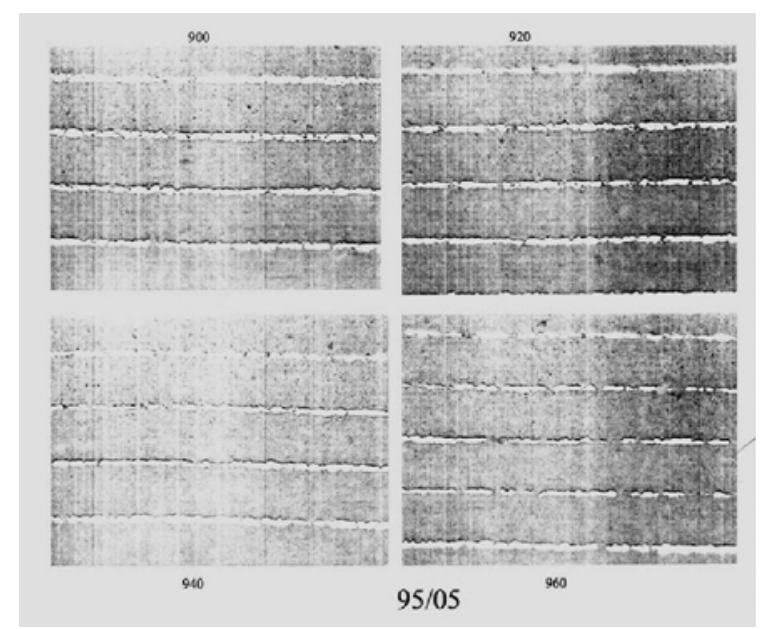

FIGURE 7 Capacitor layers produced with a 95:5 Ag/Pd powder.

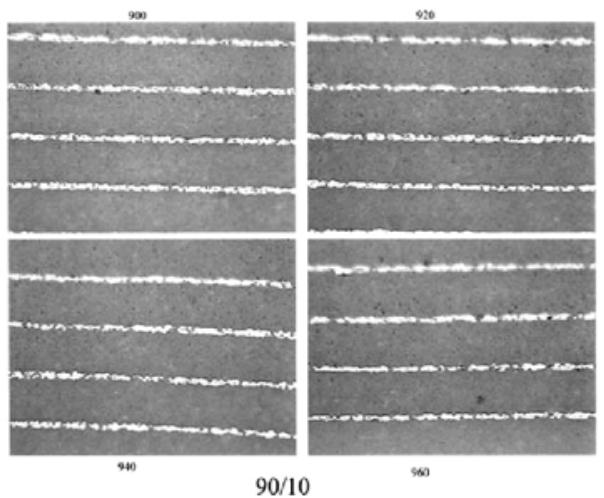

FIGURE 8 Capacitor layers produced with a 90:10 Ag/Pd powder.

From the data shown above we can conclude that both powders are suitable for producing capacitors at low sintering temperatures around $950^{\circ} \mathrm{C}$.

\section{PLATINUM VERSUS PALLADIUM}

As mentioned above, platinum prices have been much more stable and usually have lower prices than palladium. Therefore it is an advantage to be able to produce components with both alloys. We have compared NPO capacitors produced with $\mathrm{Ag} / \mathrm{Pd} 95 / 5$ and $\mathrm{Ag} / \mathrm{Pt}$ $95 / 5$ powders, see Table V. It should be emphasized that other designs have also been successfully produced with these silver/platinum powders.

From the data obtained it is obvious that the performance of the two powders is very similar, and that silver/platinum compositions are suitable for the production of capacitors inner electrodes. 
TABLE V Comparison of Electrical Performance of Powders \#455 and \#495 (95:5 Ag/Pt and $\mathrm{Ag} / \mathrm{Pd})$.

\begin{tabular}{lcc}
\hline Description & Ag/Pt $95: 5 \# 495$ & Ag/Pd $95: 5 \# 455$ \\
\hline Sintering Temp. ${ }^{\circ} \mathrm{C}$ & 940 & 940 \\
Capacity & & \\
$\quad$ Avg. (pF) & 998 & 983 \\
$\quad$ Std. & 1.30 & 3.61 \\
tanD & 3.8 & 3.1 \\
$\quad$ Max. & 0.3 & 1.1 \\
$\quad$ Min. & 1420 & 1440 \\
Breakdown voltage & 1840 & 1785 \\
$\quad$ Min. & 46.4 & 42.1 \\
$\quad$ Max. & & \\
ESR (50 MHz) & & \\
\hline
\end{tabular}

\section{CONCLUSIONS}

The nano silver/platinum powders reported in this paper are suitable for producing components, and perform in capacitors in a similar way to silver/palladium powders. The powders with low percent of precious metals (10 percent and lower) are suitable for low sintering temperatures of around $950{ }^{\circ} \mathrm{C}$. In equivalent compositions the two powder types melt in temperatures only few degrees apart, and sintering occurs in the same temperature range. Both silver/platinum and silver/palladium can be dispersed in similar paste formulations and may be printed by the same equipment. The electric performances of capacitors produced with both powder families are similar.

The ability to use both silver/palladium and silver/platinum powders in the production of NPO and X7R capacitors gives the producer the flexibility and ability to choose the powder that will be most economically suitable for him, to obtain bigger margins in the most competitive environment and higher added value.

\section{References}

[1] Kitco http://www.kitco.com/market/index.html.

[2] Smith, P. (1963). Advanced Techniques in Powder Metallurgy. Rowman \& Littlefield.

[3] Addona, T., Auger, P., Celik, C. and Chen, P. (1999). Passive component industry, 14-18.

[4] German, R. M. (1984). Powder Metallurgy Science, MPIF. 

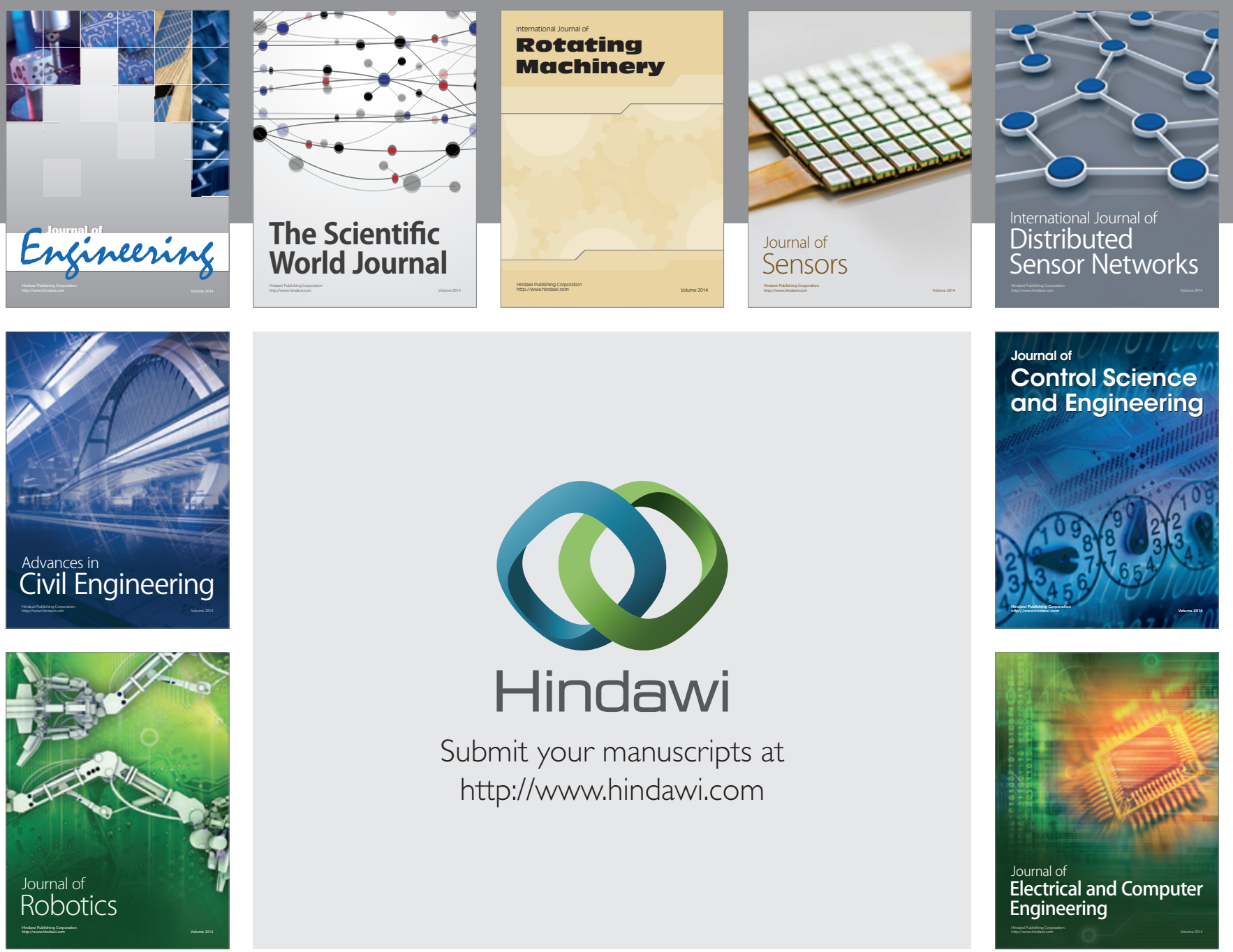

Submit your manuscripts at

http://www.hindawi.com
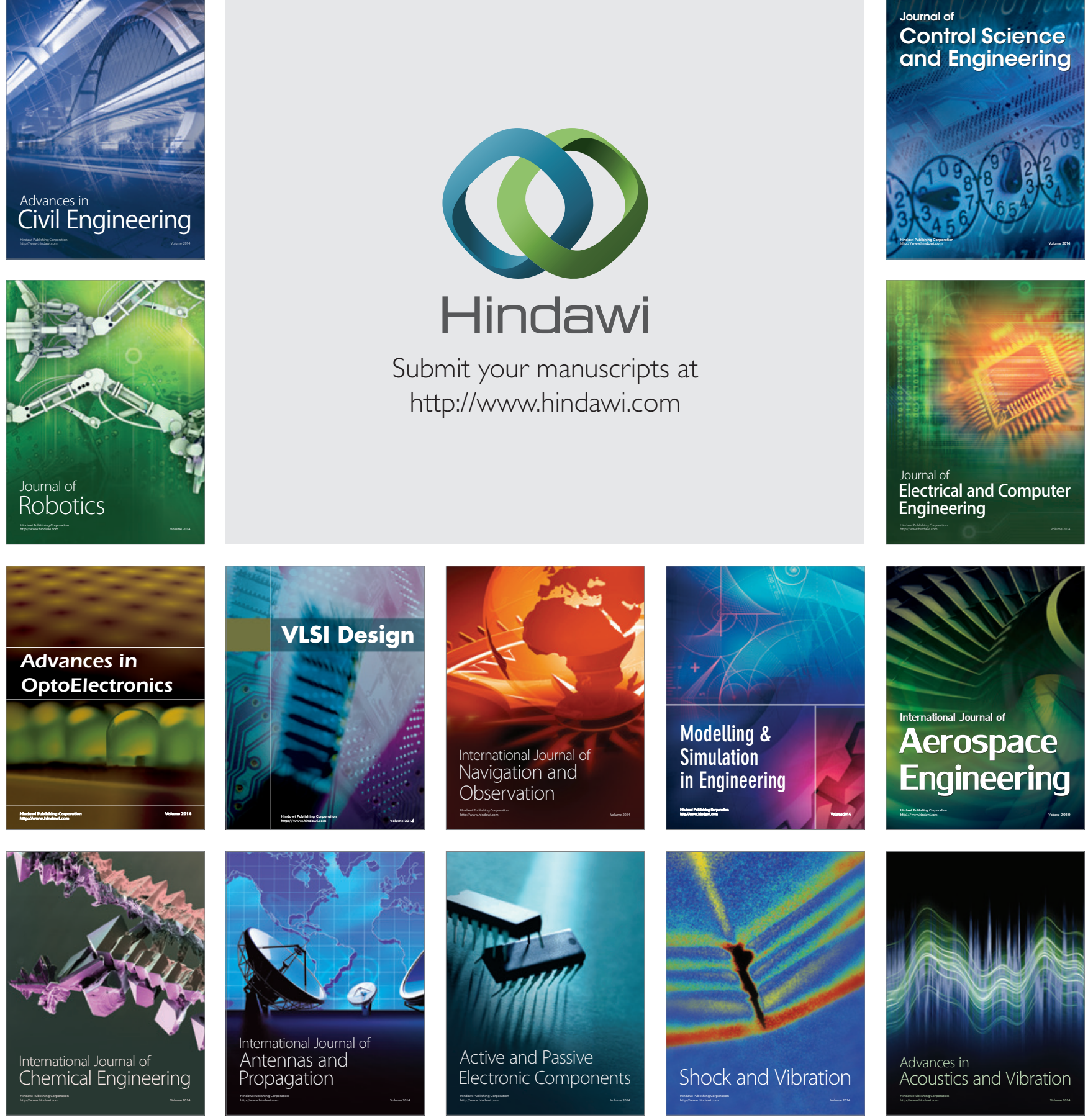